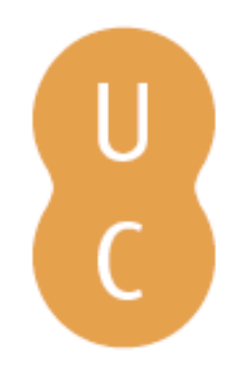

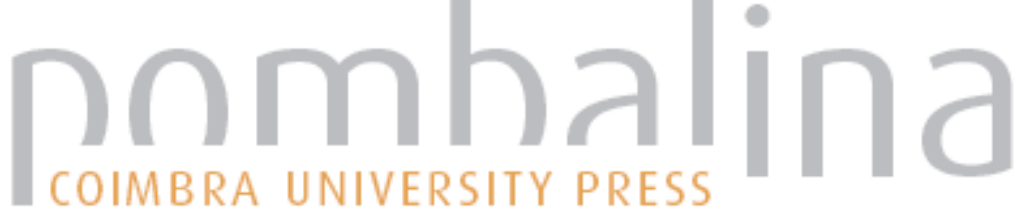

\section{Acidentes e intoxicações}

Autor(es): $\quad$ Gata, Lia

Publicado por: Imprensa da Universidade de Coimbra

URL

persistente: URI:http://hdl.handle.net/10316.2/43139

DOI: $\quad$ DOI:https://doi.org/10.14195/978-989-26-1300-0_38

Accessed : $\quad$ 26-Apr-2023 00:30:17

A navegação consulta e descarregamento dos títulos inseridos nas Bibliotecas Digitais UC Digitalis, UC Pombalina e UC Impactum, pressupõem a aceitação plena e sem reservas dos Termos e Condições de Uso destas Bibliotecas Digitais, disponíveis em https://digitalis.uc.pt/pt-pt/termos.

Conforme exposto nos referidos Termos e Condições de Uso, o descarregamento de títulos de acesso restrito requer uma licença válida de autorização devendo o utilizador aceder ao(s) documento(s) a partir de um endereço de IP da instituição detentora da supramencionada licença.

Ao utilizador é apenas permitido o descarregamento para uso pessoal, pelo que o emprego do(s) título(s) descarregado(s) para outro fim, designadamente comercial, carece de autorização do respetivo autor ou editor da obra.

Na medida em que todas as obras da UC Digitalis se encontram protegidas pelo Código do Direito de Autor e Direitos Conexos e demais legislação aplicável, toda a cópia, parcial ou total, deste documento, nos casos em que é legalmente admitida, deverá conter ou fazer-se acompanhar por este aviso.

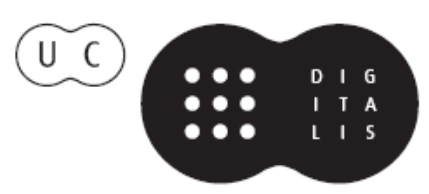




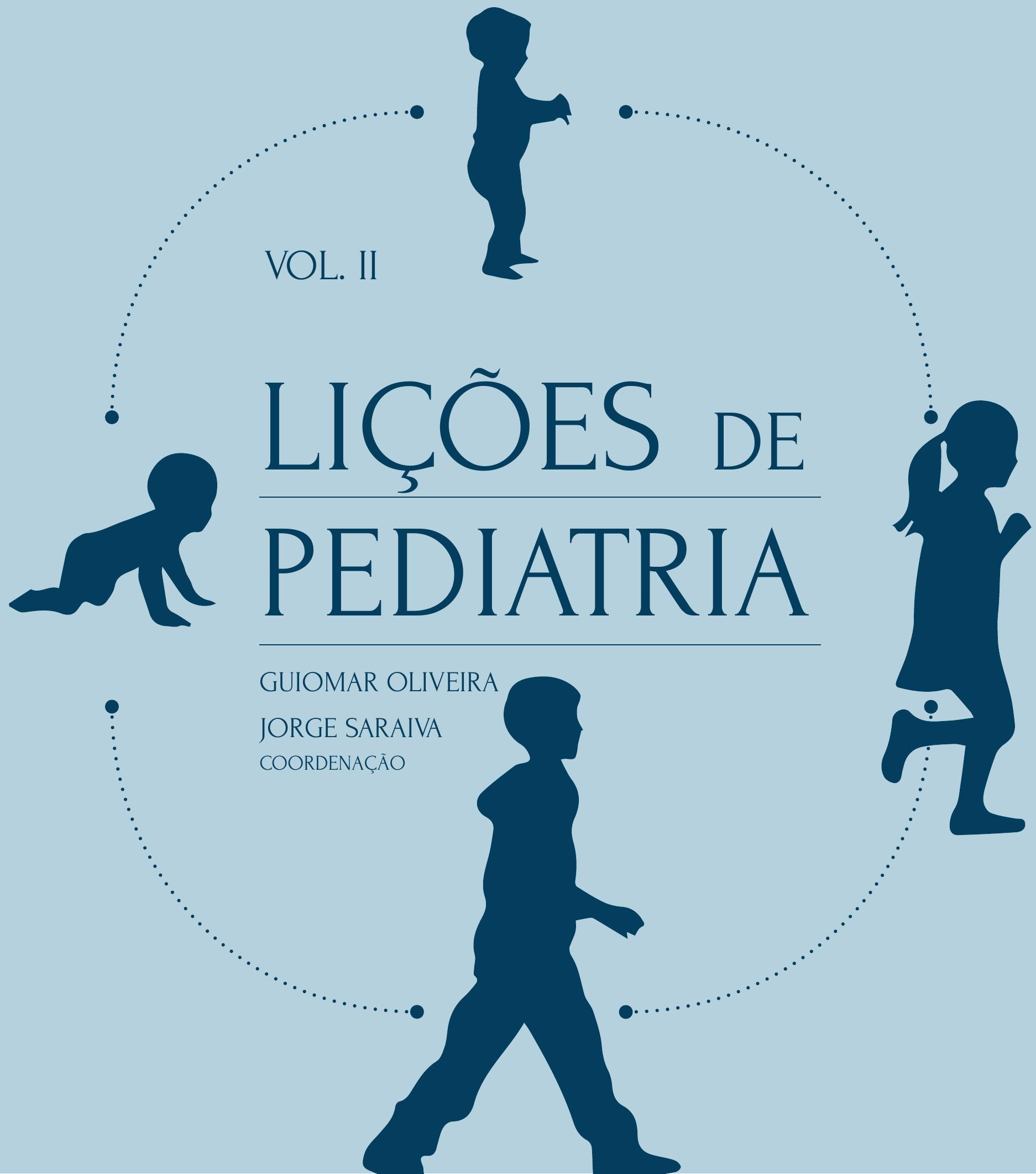


Capítulo 38.

Acidentes e intoxicações
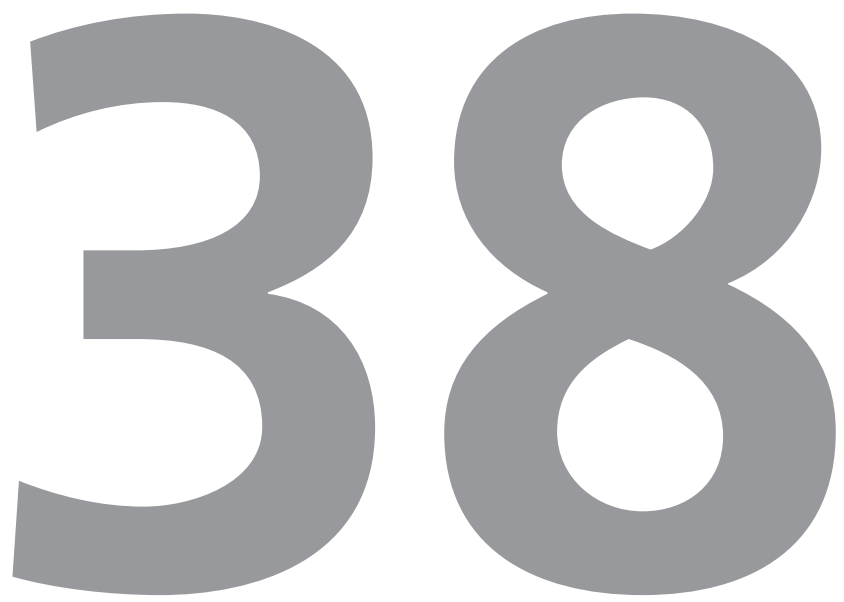

\section{Lia Gata}




\subsection{CONTEXTO}

Os acidentes são importantes causas de morbilidade (incapacidade funcional e internamento) e de mortalidade na idade pediátrica. Ao longo das últimas duas décadas, tem sido constante e consistente, a redução do número de mortes por acidente ou lesão. No entanto, as causas externas de lesão e envenenamento são a primeira causa de morte de crianças com mais de um ano de idade e de jovens até aos dezanove anos, em Portugal. Os acidentes rodoviários são a primeira causa de morte acidental.

Os traumatismos, justificaram cerca de 15\% das admissões no Serviço de Urgência do Hospital Pediátrico em 2014. As lesões traumáticas incluíram, predominantemente lesões ortopédicas, feridas e traumatismos cranianos. As queimaduras foram um motivo pouco frequente de admissão e os afogamentos foram muito raros. Na globalidade, as intoxicações acidentais foram pouco frequentes, no entanto, no grupo dos adolescentes a intoxicação voluntária representou cerca de $1 \%$ das admissões.

Nos últimos anos tem havido várias campanhas de sensibilização para a prevenção de acidentes em idade pediátrica (i.e. campanhas de prevenção de acidentes, quedas, acidentes rodoviários, afogamentos e intoxicações da Associação para a Promoção da Saúde Infantil - APSI) e mudanças importantes na legislação, como o uso obrigatório de sistemas de retenção para crianças nos automóveis e a proibição de publicidade e comércio de novas substâncias psicoactivas. No entanto, as estatísticas ainda são preocupantes. Apesar da redução da mortalidade associada a alguns tipos de acidentes, mantem-se significativo o número e sobretudo a morbilidade associada.

As crianças, entre um e cinco anos de idade, são particularmente vulneráveis aos acidentes (quedas, queimaduras, afogamento, aspiração ou ingestão de corpos estranhos e intoxicações). A aquisição progressiva de competências motoras e cognitivas, permite-lhes mobilidade e expressão do normal comportamento exploratório, no entanto, sem capacidade para reconhecer o perigo. Na idade escolar são frequentes os traumatismos por queda e aumenta o número de traumatismos por acidente rodoviário. Na adolescência predominam os traumatismos por queda ou acidente rodoviário e as intoxicações voluntárias e as intoxicações acidentais, nomeadamente com substâncias psicoativas.

\subsection{DESCRIÇÃO DO TEMA}

\subsubsection{Acidentes}

Na avaliação e tratamento de um doente que sofreu um acidente, independentemente do tipo (traumatismo, intoxicação ou outro) a prioridade é assegurar funções vitais. A metodologia $A B C D E$ [via aérea $(A)$, respiração $(B)$, circulação (C), neurológico - disability (D) e exposição (E)] é a recomendada. Esta permite avaliar e corrigir, de forma sequencial e sistematizada, a permeabilidade da via aérea (A), a ventilação e oxigenação (B), a frequência cardíaca, tensão arterial e perfusão periférica (C), o estado de consciência, tamanho e reactividade das pupilas (D) e as lesões externas (E).

Nas lesões traumáticas o tratamento da dor é, também, prioritário e deve ser assegurado logo após a avaliação primária (ABCDE). 
38.2.1.1 Aspiração de corpo estranho

A idade de maior risco situa-se entre os seis meses e os três anos. As crianças colocam objetos na boca como forma de exploração do ambiente, a mastigação é ainda imatura por ausência de molares e a via aérea é estreita.

Os corpos estranhos (CE) mais frequentemente aspirados são de origem vegetal (amendoim, castanha, tremoço ou feijão), mas qualquer objeto pode ser aspirado.

As manifestações clínicas são variadas e inespecíficas (estridor, tosse, dificuldade respiratória, febre, sibilos ou assimetria do murmúrio vesicular).

Nem sempre o episódio de engasgamento/ sufocação foi presenciado mas o seu relato é o dado clínico mais importante para o diagnóstico; estes episódios caracterizam-se por tosse, dificuldade respiratória, apneia, com ou sem cianose ou vómito.

A obstrução por CE pode ocorrer a nível da via aérea principal (laringe ou traqueia) mas mais frequentemente ocorre a nível brônquico.

Os CE localizados a nível da via aérea principal são potencialmente mais graves pelo risco de obstrução completa.

A maioria dos CE não é radiopaca e um quarto das radiografias do toráx é normal. Os achados radiológicos incluem hiperinsuflação localizada, atelectasia e consolidação pulmonar. O atraso no diagnóstico pode causar pneumonia, enfisema obstructivo e bronquiectasias ou abcessos.

A maioria das crianças apresenta obstrução parcial da via área e nestes casos será necessário garantir a oxigenação até à realização de broncoscopia que será diagnóstica e terapêutica. Nos casos em que via aérea está instável com risco de obstrução total, a manipulação da criança deve ser evitada, adiando a colocação de acesso venoso ou a realização de radiografia e deixando a criança em posição confortável, tomando as medidas necessárias para a realização emergente de broncoscopia rígida com apoio anestésico. Quando a situação evolui para paragem respiratória devem ser, de imediato, instituídas medidas de suporte básico de vida (ver lição de suporte básico de vida e noções de suporte avançado de vida).

\section{Factos a reter}

Perante uma história consistente de aspiração de CE e manifestações clínicas sugestivas deve ser realizada broncoscopia diagnóstica, mesmo que a radiografia do tórax seja normal.

\subsubsection{Ingestão de corpos estranhos}

A ingestão acidental de corpos estranhos ocorre mais frequentemente em crianças entre os seis meses e os três anos de idade. Num número significativo de casos a criança é levada ao serviço de urgência, apesar de estar assintomática, porque a ingestão foi presenciada. As manifestações clínicas mais frequentes são: salivação excessiva, recusa alimentar, disfagia e dor cervical ou retro-esternal.

A localização e tipo do corpo estranho são determinantes para a decisão de remoção por via endoscópica.

A radiografia permite a identificação e localização de corpos radiopacos (osso ou metal).

A nível esofágico existem três locais anatómicos de constrição natural onde pode ocorrer a impactação do corpo estranho: músculo cricofaríngeo, arco aórtico e esfíncter esofágico inferior.

São indicações para endoscopia urgente: piIhas tipo disco impactadas no esófago, obstrução 
esofágica por alimentos e objetos cortantes ou pontiagudos retidos no esófago ou estômago. O mecanismo principal pelo qual as pilhas tipo disco podem causar lesão grave com perfuração esofágica é a hidrólise dos tecidos adjacentes ao polo negativo da pilha onde é gerada a corrente elétrica; a lesão pode ocorrer por pressão local com risco de isquémia e por queimadura secundária ao derrame do conteúdo da pilha. Foram descritas lesões esofágicas graves apenas duas horas após ingestão de pilhas.

A ingestão de moedas raramente é uma urgência, estando indicada a sua remoção se estiverem localizadas a nível esofágico e causarem sintomas. Atenção que a localização esofágica alta pode causar obstrução da via área por compressão da traqueia.

\section{Factos a reter}

A presença de uma pilha no esófago está associada a risco elevado de lesão esofágica grave, pelo que há indicação para remoção endoscópica urgente, mesmo se decorrido pouco tempo desde a ingestão e ainda que a criança esteja assintomática.

\subsubsection{Intoxicações}

O pico de incidência das intoxicações ocorre entre o primeiro e quarto ano de vida. Um segundo pico ocorre na idade adulta, entre os 30 e os 50 anos, mas com menor expressão em termos de incidência. Na infância há um predomínio de intoxicações no sexo masculino que se inverte a partir dos dez anos e que se mantem na idade adulta. Na infância, as intoxicações são maioritariamente acidentais e resultam de vários fatores: estadío do desenvolvimento psicomotor da criança; características físicas do tóxico e da embalagem; acessibilidade ao tóxico e supervisão por adultos. A criança, sobretudo entre o um e os cinco anos, tem especial interesse pela exploração do ambiente, é atraída por substâncias coloridas ou embalagens que lhe são familiares e não tem ainda noção de risco. Se o tóxico estiver acessível e a supervisão pelos adultos for inadequada o contacto poderá ocorrer. São exemplo de situações de risco elevado, comprimidos deixados ao alcance da criança e produtos de limpeza guardados em embalagens originais ou não originais mas de uso comum (garrafa de água) acessíveis à criança. Raramente, a intoxicação resulta de doses elevadas inadvertidamente administradas.

$\mathrm{Na}$ adolescência as intoxicações são maioritariamente intencionais, com recurso a fármacos disponíveis no domicílio.

As intoxicações ocorrem maioritariamente por ingestão, no domicílio e no final do dia. $\mathrm{Na}$ infância, o pedido de ajuda e assistência é mais precoce, pelo que um número muito significativo de crianças não desenvolve sintomas. Na adolescência as intoxicações são na maioria dos casos sintomáticas, resultantes da exposição a maior quantidade de tóxico ou ingestão de múltiplos tóxicos e de pedido de ajuda e intervenção terapêutica mais tardios.

Na infância, em Portugal, os fármacos são as sustâncias mais envolvidas em intoxicações: o paracetamol com maior frequência, seguido dos anti-inflamatórios não esteróides, anti-histamínicos sistémicos, ansiolíticos (benzodiazepinas) e antipsicóticos. Os produtos de uso doméstico e industrial (lixívia de uso doméstico e detergentes manuais) ocupam o segundo lugar. Os cosméticos 
ocupam o terceiro lugar e os pesticidas o quarto. Neste último grupo destacam-se os raticidas anticoagulantes.

Também na adolescência predominam as intoxicações por fármacos, destacando-se as intoxicações por ansiolíticos, seguidas das intoxicações por outros psico-fármacos (antidepressivos e antipsicóticos). A intoxicação por etanol é, ainda, uma causa frequente de intoxicação. São raras as intoxicações com produtos de uso doméstico e industrial e com pesticidas. O número de intoxicações por novas substâncias psicoactivas (criadas e sintetizadas para imitar os efeitos de substâncias, naturais ou sintéticas, já controladas no âmbito das leis) diminuiu de forma muito significativa após a publicação, em 2013, de legislação que proíbe a venda, produção e publicidade destas substâncias, antes vendidas em "smart-shops" e on-line, sob a forma de incensos, fertilizantes e sais de banho. Estas substâncias, consumidas pelos efeitos estimulantes e alucinogénicos, podem ter efeitos adversos graves e não previsíveis uma vez que a composição e concentração são desconhecidas.

\subsubsection{Terapêutica}

Na maioria dos casos, na infância, a substância tóxica é conhecida. Por vezes a história de intoxicação é clara, no entanto a substância implicada é desconhecida, porque a família não sabe o que estava na embalagem, ou não a trouxe ou a informação do rótulo não é esclarecedora. Além da substância, pode ser determinante para a orientação terapêutica, conhecer a quantidade ingerida (dose por kilograma a que a criança foi exposta) e o tempo que decorreu desde a exposição.

Na adolescência é, habitualmente, mais difícil esclarecer quais as substâncias e dose ingeridas.
Frequentemente a exposição é múltipla. A dose de fármacos ingerida pode ser estimada se conhecido o número de comprimidos que existia no domicílio, a sua dosagem e o número de comprimidos em falta nas embalagens.

O Centro de Informação Antivenenos (CIAV), pode ser uma fonte imediata de informação sobre a toxicidade de substâncias menos conhecidas e sobre as medidas terapêuticas recomendadas.

No entanto, o mais urgente num doente exposto a uma substância tóxica é assegurar funções vitais e preservar a função de orgãos.

1. A avaliação inicial deve obedecer à metodologia de avaliação do doente crítico, ou seja, ABCDE.

2. Se disponível, outro membro da equipa deverá obter junto da família ou acompanhante informação sobre o(s) tóxico(s), dose e hora de exposição, sintomas e medidas terapêuticas instituídas (i.e. doente transferido de outra unidade de saúde onde foi administrado descontaminante intestinal).

3. A remoção do tóxico, pode diminuir a dose absorvida. O carvão ativado é a medida de descontaminação intestinal recomendada nas intoxicações por ingestão. O carvão ativado é administrado por via oral ou através de sonda nasogástrica (dose $1 \mathrm{~g} / \mathrm{kg}$ ); tem eficácia máxima na primeira hora após ingestão do tóxico, pelo que raramente tem vantagem após este período. A maioria das substâncias é adsorvida pelo carvão ativado, exceto ácidos e bases, álcoois (etanol e etilenoglicol), inseticidas e pesticidas (excluindo 
o paraquat), metais (ferro e lítio) e hidrocarbonetos. A administração do carvão ativado está contra-indicada quando a via área não está segura (i.e. doente com depressão do estado de consciência). A diluição (ingestão de água ou leite) e a indução do vómito com xarope de ipeca, estão contra-indicados. A lavagem gástrica prévia à administração de carvão ativado não tem vantagem adicional para a redução da absorção intestinal dos tóxicos.

4. São poucos os tóxicos com antídotos e a sua administração não tem prioridade sobre as intervenções que visam assegurar as funções vitais. São exemplos de antídotos, a $\mathrm{N}$-acetlcisteína para o paracetamol, a naloxona para os opiáceos e o flumazenil para as benzodiapepinas.

5. A avaliação inicial, na intoxicação aguda, tem especificidades: ABCD3EF.

O D3 inclui: disability (estado de consciência, tamanho e reactividade das pupilas), drugs e decontamination. O E representa electrocardiogram e o F fever. A hipoglicémia pode ser a causa de alteração do estado de consciência ( $D$ - disability) e deve ser corrigida nesta fase com bólus de glicose endovenosa ( $D$ - drugs), se não foi previamente diagnosticada. Um doente em coma com pupilas mióticas deve evocar uma intoxicação por opiáceos (D - disability) e neste caso está indicada a administração do antídoto naloxona (D - drugs); nesta fase há também indicação para descontaminação urgente, por exemplo remoção de caústico a nível ocular (D - decontamination). No E devem ser diagnosticadas e tratadas as alterações electrocardiográficas com risco de arritmia, por exemplo prolongamento do QRS por intoxicação com antidepressivos tricíclicos. A hipertermia (F) pode ser um sinal de intoxicação (i.e. salicilatos).

\subsubsection{Tóxicos específicos}

\section{Ingestão de Paracetamol}

A toxicidade por paracetamol pode causar falência hepática aguda. Nas primeiras horas o doente está assintomático e os sintomas iniciais são inespecíficos (náuseas e vómitos). A elevação das transaminases tem início após as primeiras 24 horas.

Não ocorrerá toxicidade hepática, se a administração do antídoto ( $\mathrm{N}$-acetilcisteína) for iniciada nas primeiras oito horas (duração da perfusão endovenosa - 21 horas). Uma dose ingerida superior a $150 \mathrm{mg} / \mathrm{kg}$ ou 7,5 g (adulto) tem risco de toxicidade. O nível sérico de paracetamol e a sua interpretação de acordo com a curva de toxicidade do nomograma $(100 \mathrm{mg} / \mathrm{L}$ à quarta hora após ingestão), determinam a indicação para tratamento com $\mathrm{N}$-acetilcisteína. O nomograma só pode ser utilizado a partir da quarta hora após ingestão.

\section{Ingestão de benzodiazepinas}

Os sintomas mais comuns são: sonolência, incoordenação motora, ataxia e disartria. Na intoxicação acidental o quadro é habitualmente ligeiro, de início súbito e regride rapidamente, pelo que será necessária observação no serviço de urgência durante algumas horas. A ingestão é comprovada pela deteção de benzodiazepinas na urina. 
Na intoxicação grave com depressão do estado de consciência e depressão respiratória, está indicada a administração do antídoto, flumazenil. A oxigenação deve ser assegurada, se necessário com suporte ventilatório ( $B$ da avaliação $A B C D E F$ ), tendo esta prioridade sobre a administração do antídoto.

\section{Ingestão de etanol}

A intoxicação ligeira carateriza-se por: alteração do humor com desinibição, euforia e verborreia ou discurso lentificado e vómitos; a intoxicação grave causa depressão do estado de consciência. O hálito etílico é um dado clínico que auxilia no diagnóstico. O nível sérico de etanol correlaciona-se com a gravidade clínica e a sua determinação está indicada na intoxicação moderada ou grave, se dúvida diagnóstica ou se traumatismo (i.e. doente em coma e com sinais de traumatismo por queda). A hipoglicémia e a hipotermia são as complicações mais frequentes.

Na intoxicação moderada ou grave é prioritário assegurar funções vitais (ABCDEF) e corrigir a hipoglicémia com glicose endovenosa e a hipotermia com medidas de aquecimento externo. A administração de carvão ativado só tem utilidade se houver co-ingestão de substâncias absorvíveis.

A maioria dos casos ligeiros ou moderados regride em horas.

\section{Ingestão de raticidas}

Os raticidas mais comercializados em Portugal são as superwarfarinas; têm potência e semi-vida superior à da warfarina, dos raticidas de primeira geração. As superwarfarinas inibem a síntese de fatores da coagulação dependentes da vitamina $K$, pelo que a sua toxicidade se traduz por prolongamento do tempo de protrombina (TP) e aumento do índice internacional normalizado (INR). As alterações analíticas precedem as manifestações hemorrágicas e podem ser detetadas ao fim das primeiras 24 horas.

$\mathrm{Na}$ intoxicação acidental, a dose ingerida é habitualmente muito pequena (menos de um bloco de raticida) e o risco de toxicidade é quase inexistente. Nestes casos, a vigilância pode ser efetuada no domicílio, recomendando-se no entanto a determinação do TP e INR às 24 e às 48 horas após ingestão. A ausência de coagulopatia às 48 horas exclui toxicidade.

Na ingestão de doses tóxicas (intoxicação intencional), está indicada a administração de carvão activado na primeira hora. Neste caso, será necessária a vigilância clínica no hospital, com monitorização do TP e INR. A administração profilática de vitamina $K$ não tem vantagem e a vitamina K só está indicada em quadro de coagulopatia e enquanto este persistir.

\section{Ingestão de Caústicos}

A ingestão acidental de caústicos por crianças resulta do acondicionamento do produto em embalagens não originais (i.e. garrafas de água) e da utilização indevida no domicílio de produtos de uso industrial (altamente corrosivos), deixados ao alcance da criança. As substâncias mais frequentemente implicadas têm pH alcalino e estão presentes em produtos de limpeza doméstica e industrial.

É importante identificar o produto e o $\mathrm{pH}$ do mesmo (potência do ácido ou da base) para prever a gravidade das lesões associadas. 
O hipoclorito de sódio (lixívia doméstica) é uma base fraca, que apenas poderá causar irritação das mucosas, não estando indicada qualquer medida terapêutica.

Os sintomas e sinais mais frequentes resultantes da ingestão de cáusticos são: lesões orais e faríngeas por corrosão, salivação, disfagia, vómitos, dor abdominal e em casos graves obstrução da via área superior por edema laríngeo.

Estão contra-indicados, a diluição com água ou leite, ou a indução de vómito. A avaliação endoscópica de lesões esofágicas deve ser realizada sempre que haja forte suspeita de ingestão, mesmo que não estejam presentes lesões orais. O tratamento com inibidores da bomba de protões está recomendado quando há lesão esofágica. A utilização de corticoides é controversa e o seu uso não está recomendado. A antibioterapia de largo espetro está indicada quando há evidência de perfuração esofágica. A manutenção do tratamento depende da presença e gravidade das lesões de esofagite. A estenose esofágica é a complicação mais frequente.

\section{Maus tratos}

Deve ser considerada a hipótese de maus tratos: em crianças com idade inferior a 12 meses ou compreendida entre os seis e os 11 anos (idades em que as intoxicações acidentais são menos frequentes), quando a história descrita pelos cuidadores é inconsistente, a dose de tóxico a que a criança foi exposta é elevada, estão envolvidos múltiplos tóxicos ou substâncias de abuso, há antecedentes familiares de intoxicação (i.e. irmãos) e quando há evidência de outras formas de abuso ou negligência.

\section{Factos a reter}

1.A intoxicação por paracetamol pode ser assintomática nas primeiras horas e os sintomas iniciais são inespecíficos. Um nível sérico acima da curva do nomograma, quatro horas ou mais após ingestão, indica necessidade de tratamento com antídoto. Se a administração de $\mathrm{N}$-acetilcisteína for iniciada nas primeiras oito horas, será evitada a hepatoxicidade.

2.Suspeitar de intoxicação por benzodiazepinas, se quadro sugestivo e de início súbito, em crianças de um a cinco anos. Nestes casos a deteção de benzodiazepinas na urina é útil.

3.A intoxicação etílica deve ser considerada possível em jovens com alteração do estado de consciência. Na intoxicação não presenciada o hálito etílico é orientador e a determinação do nível sérico é um indicador adicional da gravidade. A hipoglicémia é uma complicação frequente.

4.0 risco de toxicidade por superwarfarinas é mínimo quando foi ingerida pequena quantidade, o que acontece nas intoxicações acidentais em crianças. Nas ingestões voluntárias, o risco de toxicidade é superior, pois as doses ingeridas são habitualmente elevadas. A alteração do INR e do TP pode ocorrer até às 48 horas, sem qualquer sintomatologia acompanhante.

5. A lixívia doméstica é um produto com toxicidade mínima e a sua ingestão não implica medidas terapêuticas.

6.Na ingestão de caústicos a avaliação endoscópica de lesões esofágicas deve ser 
realizada mesmo que não haja lesões orais.

7.A intoxicação aguda pode ser uma forma de apresentação de maus tratos, sobretudo em crianças com idades não compreendidas entre um e os cinco anos, quando são mais frequentes as intoxicações acidentais.

\subsubsection{Prevenção}

A prevenção de acidentes é a medida mais determinante para a redução da mortalidade em idade pediátrica, em Portugal.

Entre múltiplas medidas preventivas, de grande impacto, destacam-se:

- uso correto e sistemático de sistemas de retenção para crianças nos automóveis.

- utilização do cinto de segurança.

- utilização correta e sistemática de capacete pelas crianças e adolescentes.

- redução da velocidade junto de estabelecimentos educativos e zonas residenciais.
- proteção de piscinas e outros planos de água construídos em edifícios residenciais, estabelecimentos educativos e espaços de lazer.

- alterações nas construções de forma a evitar quedas de janelas de edifícios com mais de um andar (i.e. guardas ou limitadores de abertura).

- obrigatoriedade de embalagens de medicamentos com abertura resistente às crianças.

- embalagens de produtos de utilização doméstica com abertura resistente às crianças.

- os cuidados no acondicionamento e arrumação de produtos de utilização doméstica.

- divulgação de informação e recomendações de segurança sobre o risco de asfixia com alimentos, balões, sacos de plástico, bolsas de transporte, fios de estores/cortinas e cordões da roupa.

- divulgação, junto dos jovens, dos riscos do consumo de substâncias psicoativas. 